\title{
Forecasting the Wuhan coronavirus (2019-nCoV) epidemics using a simple (simplistic) model
}

\author{
Slav W. Hermanowicz, Ph.D. \\ Tsinghua-Berkeley Shenzhen Institute \\ Department of Civil and Environmental Engineering \\ University of California, Berkeley, CA 94720, USA \\ e-mail: hermanowicz@ce.berkeley.edu
}

\author{
Version 1: February 3, 2020 14:21 GMT+8 \\ Version 2: February 4, 2020 07:24 GMT+8 \\ Version 3: February 8, 2020 16:13 GMT+8
}

\begin{abstract}
Findings
Confirmed infection cases in mainland China were analyzed using the data up to January 28, 2020 (first 13 days of reliable confirmed cases). For the first period the cumulative number of cases followed an exponential function. However, from January 28, we discerned a downward deviation from the exponential growth. This slower-than-exponential growth was also confirmed by a steady decline of the effective reproduction number. A backtrend analysis suggested the original basic reproduction number $R_{0}$ to be about 2.4 to 2.5. As data become available, we subsequently analyzed them during three consecutive periods obtaining a sequence of model predictions. All available data up were processed the same way. We used a simple logistic growth model that fitted very well with all data. Using this model and the three sets of data, we estimated maximum cases as about 21,000, 28,000 and 35,000 cases refining these predictions in near-real time. With slightly different approach (linearization in time) the estimate of maximum cases was even higher (about 65,000). Although the estimates of maximum cases increase as more data were reported all models show reaching a peak in mid-February in contrast to the unconfined exponential growth. These predictions do not account for any possible other secondary sources of infection.
\end{abstract}

\section{Introduction}

Recent outbreak of a novel coronavirus (designated 2019-nCoV) originated in Wuhan, China raised serious public health concerns and many human tragedies. To manage the epidemics resulting from virus spreading across China and other countries forecasting the occurrence of future cases is extremely important. Such forecasting is very complicated and uncertain since many factors are poorly understood or estimated with a large possible error. Two major factors include spatial movement of virus carriers (i.e., infected individuals) and the basic reproduction number $\mathrm{R}_{0}$ (average number of new infections originated from an infected individual).

As a result of great public attention to the virus spreading several approaches were recently reported attempting to model the epidemics and infection dynamics (Chen et al., 2020; Hui et al., 2020; Imai, Cori, et al., 2020; Imai, Dorigatti, Cori, Donnelly, et al., 2020; Li et al., 2020; Linton 
et al., 2020; Liu et al., 2020; Shen, Peng, Xiao, \& Zhang, 2020; Wu, Leung, \& Leung, 2020;

Zhang \& Wang, 2020b; Zhao et al., 2020a). These models are certainly useful to understand the implications of various quarantine procedures, public health actions, and possible virus modifications. However, the reported models are, by its nature, very complicated with numerous assumptions and requiring many parameters values of which are not known with good accuracy. As a result, some predictions (Nishiura et al., 2020) were more educated guesses although eventually they were confirmed qualitatively.

In this work, we present the results of fitting a very simple (perhaps even simplistic) model to the available data and a forecast of new infections.

\section{Logistic Model and its Application}

The logistic model has been used in population dynamics and specifically in epidemics for a long time (Bailey, 1950; Bangert, Molyneux, Lindsay, Fitzpatrick, \& Engels, 2017; Cockburn, 1960; Jowett, Browning, \& Haning, 1974; Koopman, 2004; Mansfield \& Hensley, 1960; Waggoner \& Aylor, 2000). Mathematically, the model describes dynamic evolution of a population $P$ (in our case the number of infected individuals) being controlled by the growth rate $r$ and population capacity $K$ due to limiting resources. In continuous time $t$ the change of $P$ is

$$
d P / d t=r P\left(1-\frac{P}{K}\right)
$$

Initially, the growth of $P$ is close to exponential since the term $(1-P / K)$ is almost one. When $P$ becomes larger (commensurate with $K$ ) the growth rate slows down with

$$
r_{e}=r\left(1-\frac{P}{K}\right)
$$

becoming an effective instantaneous growth rate.

In discrete time, more appropriate to daily reported infection cases, the logistic model becomes

$$
P(t+1)=R_{0}^{*} P(t)\left[1-\frac{P(t)}{K}\right]
$$

where $P(t)$ and $P(t+1)$ are populations on consecutive days, $\mathrm{R}_{0}{ }^{*}$ is the growth rate (basic reproduction number in epidemiology) at the beginning of the logistic growth, and $K$ is the limiting population. When plotted as a function of time $t$, both Eqs. (1) and (3) result in a classic sigmoidal curve with

$$
R_{e}=R_{0}^{*}\left[1-\frac{P(t)}{K}\right]
$$

being the effective reproduction rate at time $t$.

The logistic model may be adequate for the analysis of mainland China since the country can be treated as a unit where a vast majority of cases occurred without any significant "import" or "export" of cases. 


\section{Data Analysis}

We analyzed infection cases in mainland China as reported by the National Health Commission of the People's Republic of China (www.nhc.gov.cn/xcs/xxgzbd/gzbd_index.shtml). As of the time of writing the number of cases is shown in Table 1 . The data are also plotted in Figure 1. The first column in Table 1 represents days from the beginning of the outbreak. There is a considerable controversy as to the exact date of the outbreak with most reports pointing to midDecember (Li et al., 2020; Wang, Horby, Hayden, \& Gao, 2020) while one analysis suggest multiple sources of original infection (Nishiura et al., 2020). Initially, the outbreak was not recognized and number of confirmed cases is not fully known (P. Wu et al., 2020). Initially, (Figure 1), the number of cases increased exponentially. This feature was also clearly recognized in a previous report (Zhao et al., 2020b).

Table 1 Reported cases in mainland China

\begin{tabular}{|c|c|c|c|}
\hline Day & Date & Cases & $\mathbf{R}_{\mathbf{e}}$ \\
\hline 30 & January 16, 2020 & 45 & \\
\hline 31 & January 17, 2020 & 62 & 1.38 \\
\hline 32 & January 18, 2020 & 121 & 1.95 \\
\hline 33 & January 19, 2020 & 198 & 1.64 \\
\hline 34 & January 20, 2020 & 291 & 1.47 \\
\hline 35 & January 21, 2020 & 440 & 1.51 \\
\hline 36 & January 22, 2020 & 571 & 1.30 \\
\hline 37 & January 23, 2020 & 830 & 1.45 \\
\hline 38 & January 24, 2020 & 1,287 & 1.55 \\
\hline 39 & January 25, 2020 & 1,975 & 1.53 \\
\hline 40 & January 26, 2020 & 2,744 & 1.39 \\
\hline 41 & January 27, 2020 & 4,515 & 1.65 \\
\hline 42 & January 28, 2020 & 5,974 & 1.32 \\
\hline 43 & January 29, 2020 & 7,711 & 1.29 \\
\hline 44 & January 30, 2020 & 9,692 & 1.26 \\
\hline 45 & January 31, $2020^{(1)}$ & 11,860 & 1.22 \\
\hline 46 & February 1, 2020 & 14,380 & 1.21 \\
\hline 47 & February 2, 2020 & 17,307 & 1.20 \\
\hline 48 & February $3,2020^{(2)}$ & 20,467 & 1.18 \\
\hline 49 & February 4, 2020 & 24,324 & 1.19 \\
\hline 50 & February 5, 2020 & 28,018 & 1.15 \\
\hline 51 & February 6, 2020(3) & 31,161 & 1.11 \\
\hline 52 & February 7, 2020 & 31,774 & 1.02 \\
\hline 53 & February 8, 2020 & 33,738 & 1.06 \\
\hline 54 & February 9, 2020 & & \\
\hline
\end{tabular}

(1), (2), (3) - ends of Periods 1, 2, and 3. Data beyond Feb. 6 were not used in model fitting and predictions 
However, starting from January 28 (day 42) there was a marked deviation from the exponential curve, in line with logistic growth. This decline of the growth rate is clearly demonstrated by a steady decline of the effective reproduction number $R_{e}$ (fourth column in Table 1 ) calculated simply as a ratio of cases on consecutive days

$$
R_{e}(t)=\left[\frac{P(t+1)}{P(t)}\right]=R_{0}^{*}\left(1-\frac{P(t)}{K}\right)=R_{0}^{*}-\left[\frac{R_{0}^{*}}{K}\right] P(t)
$$

Eq. (5) also shows a linearization of the discrete logistic model (Eq. (3)) that was used to estimate the $R_{e}(t=30)=R_{0}{ }^{*}$ and capacity $K$. An example of such linearization for Period 1 is shown in Figure 2 with the initial 16 points (blue points and line in Figure 2). The same figure also shows linearization using for Period 2 (orange points and line in Figure 2 ). For all periods the effective reproduction numbers decrease in time.

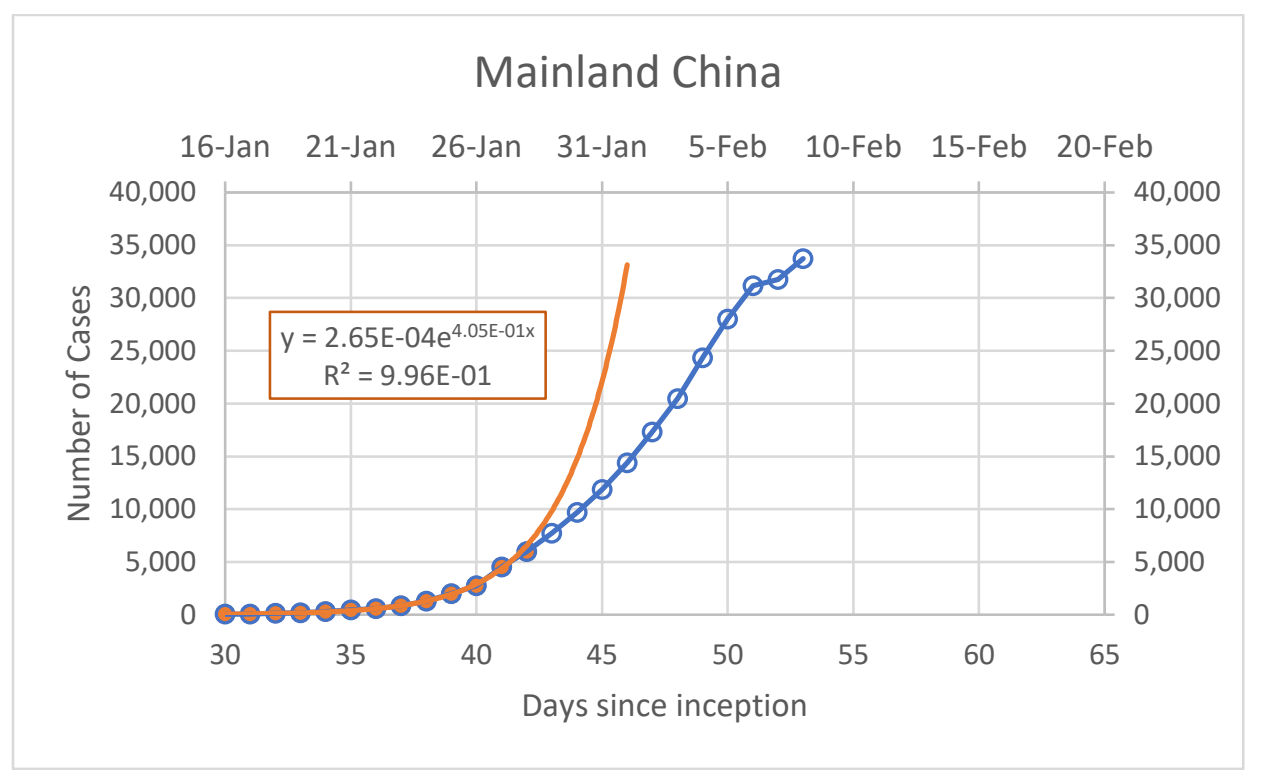

Figure 1 Evolution of recorded infection cases. From day 42 there is a significant slowing of the infections.

As new data were reported daily, we followed with subsequent analysis in near-real time with three periods as shown in Table 2

Table 2 Consecutive model refinements

\begin{tabular}{|c|c|c|c|c|c|}
\hline \multicolumn{2}{|c|}{ Period End } & \multirow[t]{2}{*}{$\boldsymbol{R}_{0}{ }^{*}$} & \multirow[t]{2}{*}{$K$} & \multirow{2}{*}{$\begin{array}{l}\text { Maximum } \\
\text { cases }\end{array}$} & \multirow{2}{*}{$\begin{array}{l}\text { Peak time } \\
\text { (day) }\end{array}$} \\
\hline Day & Date & & & & \\
\hline 45 & January 31 & 1.52 & $6.2 \cdot 10^{4}$ & $3.52 \cdot 10^{4}$ & 56 \\
\hline 48 & February 3 & 1.48 & $8.6 \cdot 10^{4}$ & $2.81 \cdot 10^{4}$ & 57 \\
\hline 51 & February 6 & 1.48 & $1.1 \cdot 10^{5}$ & $3.52 \cdot 10^{4}$ & 60 \\
\hline
\end{tabular}




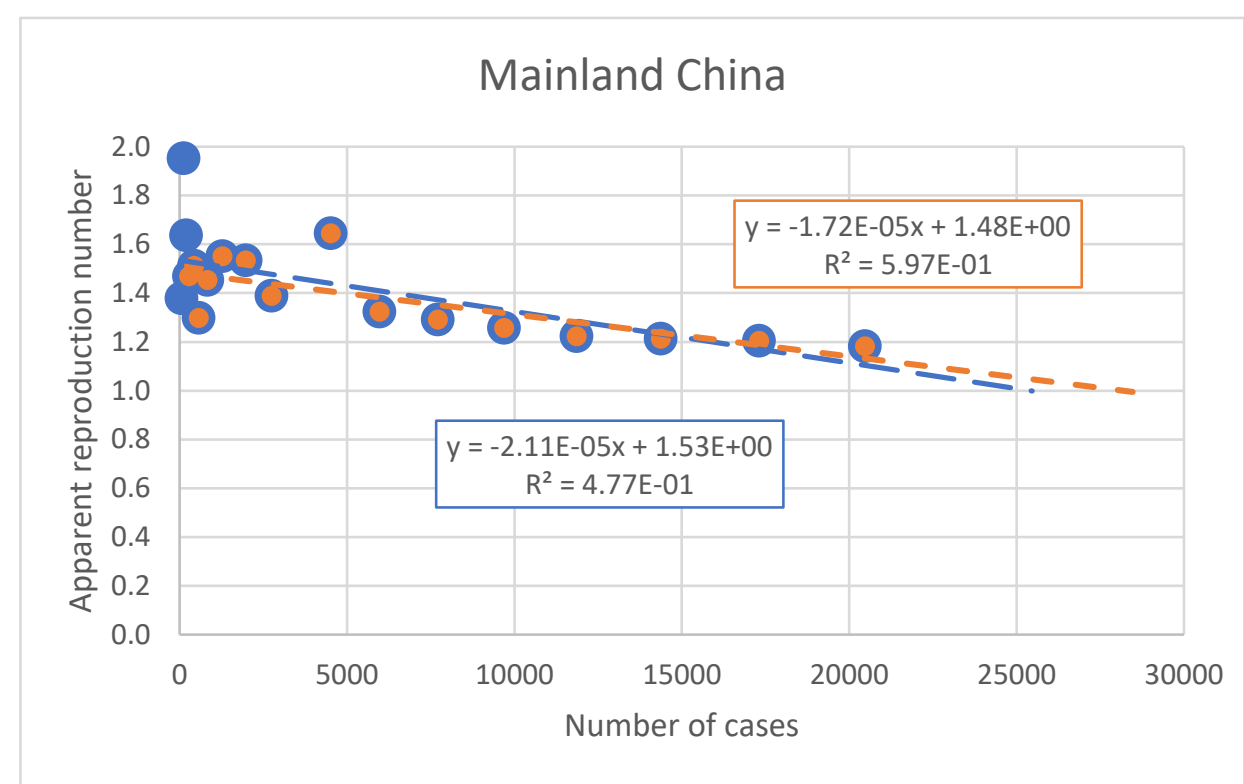

Figure 2 Linearization of the effective reproduction number with number of cases following Eq. (5) for Periods 1 and 2

In contrast, a simple linearization of $R_{e}$ in time (Figure 3) back-estimated the original basic reproduction number $R_{0}$ at about 2.4 to 2.5, agreeing well with other values recently reported (Imai, Dorigatti, Cori, Riley, \& Ferguson, 2020; Liu et al., 2020; Majumder \& Mandl, 2020; Zhang \& Wang, 2020a, 2020b; Zhao et al., 2020a). The discrepancy between these two estimates can be attributed a potential loss of virulence of the virus but most likely due to extreme measures to contain virus spread in China.

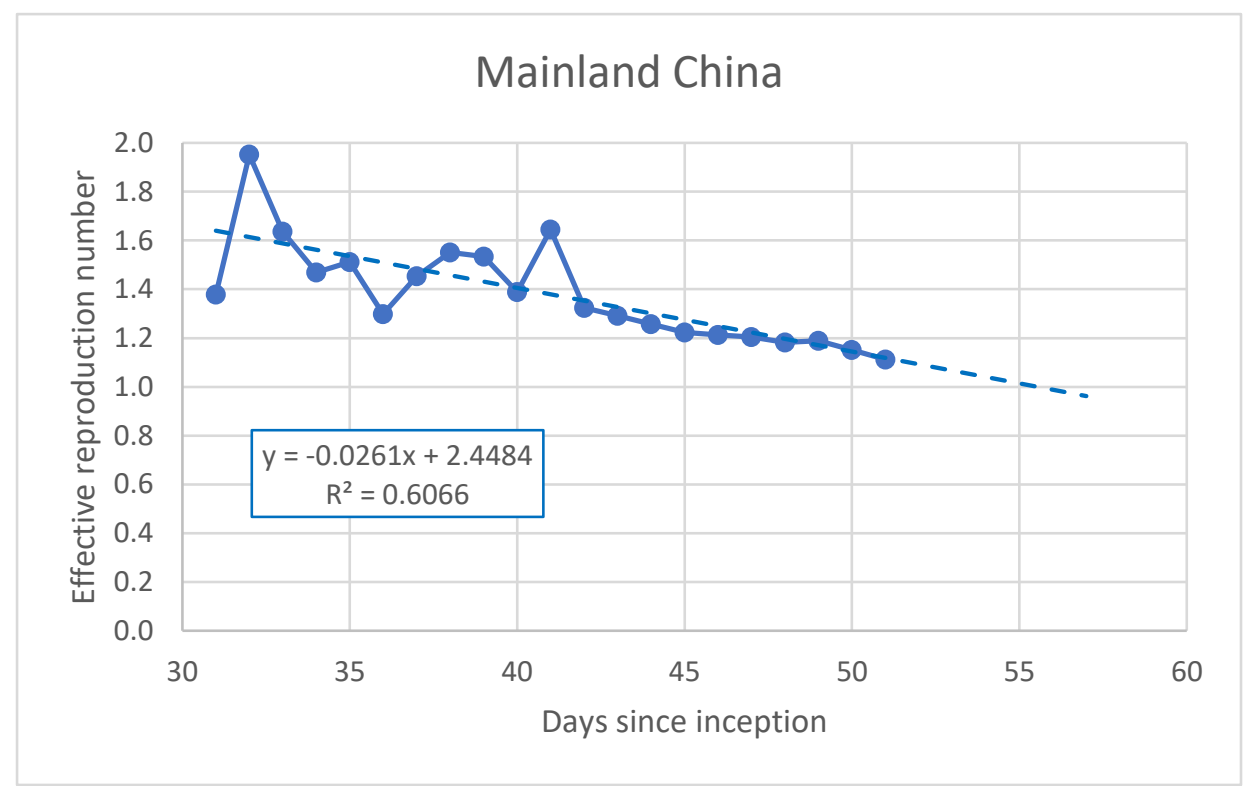

Figure 3 Linearization of the effective reproduction number with time 
This linearization provides yet another method for the use of the logistic model. We use linear regression as shown in Figure 3 to calculate the effective reproduction numbers for a series of days $R_{e}{ }^{*}(t)$ with the ${ }^{*}$ superscript denoting that the values are calculated from the regression. Using Eqs. (3) and (4) the predicted values of $P(t)$ can be calculated regressively as

$$
P(t+1)=R_{e}^{*}(t) P(t)
$$

\section{Forecast and Discussion}

Based on the linearization of Eq. (5), we obtained the parameters of the logistic model for three periods as shown in Table 2. The resulting prediction of future infection cases are shown in Figure 4

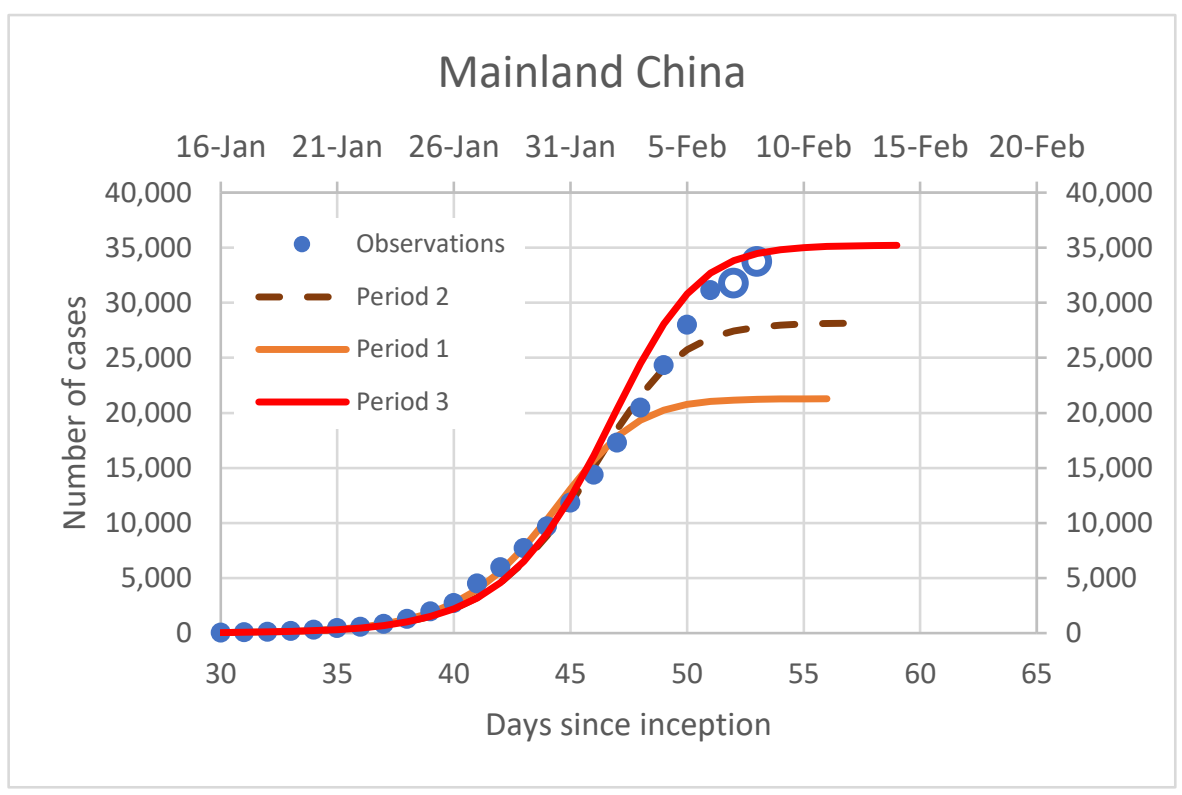

Figure 4 Recorded infection cases and model predictions for three periods analyzed. Data up to day $51=$ February 6 were used for model fitting. Open circle newest data point not included in the model fitting

The model predicted further increases of the infected cases but slower than the initial exponential growth. As expected, new data resulted in further model refinement primarily in the values of $K$ and the resulting maximum cases.

Following a parallel approach and using Eq. (6) we obtained yet another set of predictions shown in together with those from Figure 4. This approach results in a dramatically higher predictions 
of maximum case (at about 65,000) but remarkably shows a very close time for the peak (Figure 5).

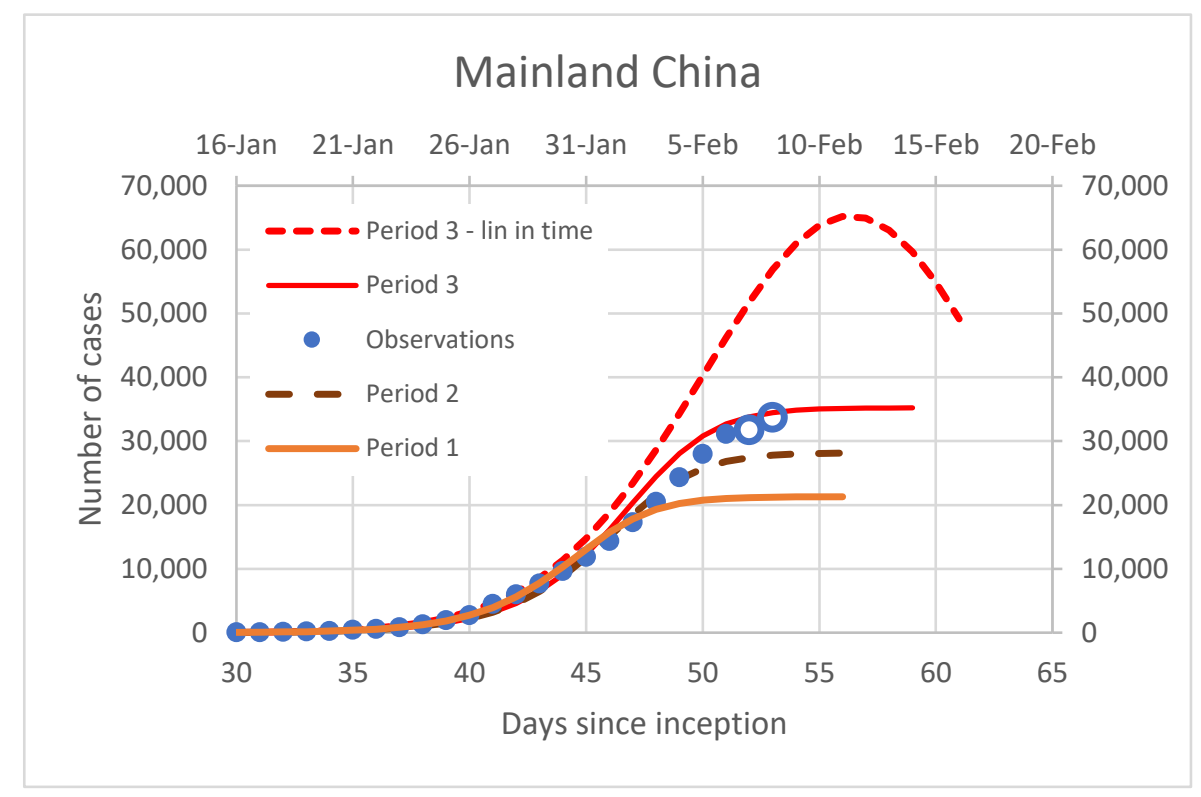

Figure 5 Predictions of model using linearization in time (Eq. 6) together with those of Figure 4. Open circle - newest data point not included in the model fitting

Despite differences among different estimate, the critical feature of the model predictions is the stabilization of the total number of cases in the next several days (by mid-February) and not a dramatic exponential growth. This prediction is made purely based on the described analysis and may or may not happen in the future. One significant factor that could invalidate the predictions is a possibility of secondary or parallel outbreaks perhaps with different etiology as previously suggested for the original Wuhan outbreak (P. Wu et al., 2020) 


\section{Declarations}

\section{Ethics approval and consent to participate}

The ethical approval or individual consent was not applicable.

\section{Availability of data and materials}

All data and materials used in this work were publicly available.

\section{Consent for publication}

Not applicable.

\section{Funding}

This work was not funded.

\section{Disclaimer}

The funding agencies had no role in the design and conduct of the study; collection, management, analysis, and interpretation of the data; preparation, review, or approval of the manuscript; or decision to submit the manuscript for publication.

\section{Conflict of Interests}

The author declared no competing interests.

\section{References}

Bailey, N. T. J. (1950). A SIMPLE STOCHASTIC EPIDEMIC. Biometrika, 37(3-4), 193-202. doi:10.1093/biomet/37.3-4.193

Bangert, M., Molyneux, D. H., Lindsay, S. W., Fitzpatrick, C., \& Engels, D. (2017). The crosscutting contribution of the end of neglected tropical diseases to the sustainable development goals. Infectious Diseases of Poverty, 6. doi:10.1186/s40249-017-0288-0

Chen, T., Rui, J., Wang, Q., Zhao, Z., Cui, J.-A., \& Yin, L. (2020). A mathematical model for simulating the transmission of Wuhan novel Coronavirus. bioRxiv, 2020.2001.2019.911669. doi:10.1101/2020.01.19.911669

Cockburn, T. A. (1960). EPIDEMIC CRISIS IN EAST PAKISTAN - APRIL-JULY, 1958. Public Health Reports, 75(1), 26-36. doi:10.2307/4590706

Hui, D. S., I Azhar, E., Madani, T. A., Ntoumi, F., Kock, R., Dar, O., . . Petersen, E. (2020). The continuing 2019-nCoV epidemic threat of novel coronaviruses to global health \&\#x2014; The latest 2019 novel coronavirus outbreak in Wuhan, China. International Journal of Infectious Diseases, 91, 264-266. doi:10.1016/j.ijid.2020.01.009

Imai, N., Cori, A., Dorigatti, I., Baguelin, M., Donnelly, C., Riley, S., \& Ferguson, N. M. (2020). Report 3: Transmissibility of 2019-nCoV Retrieved from London, UK: https://www.imperial.ac.uk/media/imperial-college/medicine/sph/ide/gidafellowships/Imperial-2019-nCoV-transmissibility.pdf

Imai, N., Dorigatti, I., Cori, A., Donnelly, C., Riley, S., \& Ferguson, N. M. (2020). Report 2: Estimating the potential total number of novel Coronavirus cases in Wuhan City, China Retrieved from London, UK: https://www.imperial.ac.uk/media/imperialcollege/medicine/sph/ide/gida-fellowships/2019-nCoV-outbreak-report-22-01-2020.pdf

Imai, N., Dorigatti, I., Cori, A., Riley, S., \& Ferguson, N. M. (2020). Report 1: Estimating the potential total number of novel Coronavirus (2019-nCoV) cases in Wuhan City, China Retrieved from London, UK: https://www.imperial.ac.uk/media/imperialcollege/medicine/sph/ide/gida-fellowships/2019-nCoV-outbreak-report-17-01-2020.pdf 
Jowett, D., Browning, J. A., \& Haning, B. C. (1974). NONLINEAR DISEASE PROGRESS CURVES.

Koopman, J. (2004). Modeling infection transmission. Annual Review of Public Health, 25, 303326. doi:10.1146/annurev.publhealth.25.102802.124353

Li, Q., Guan, X., Wu, P., Wang, X., Zhou, L., Tong, Y., . . Feng, Z. (2020). Early Transmission Dynamics in Wuhan, China, of Novel Coronavirus-Infected Pneumonia. New England Journal of Medicine. doi:10.1056/NEJMoa2001316

Linton, N. M., Kobayashi, T., Yang, Y., Hayashi, K., Akhmetzhanov, A. R., Jung, S.-m., . . . Nishiura, H. (2020). Epidemiological characteristics of novel coronavirus infection: A statistical analysis of publicly available case data. medRxiv, 2020.2001.2026.20018754. doi:10.1101/2020.01.26.20018754

Liu, T., Hu, J., Kang, M., Lin, L., Zhong, H., Xiao, J., . . Ma, W. (2020). Transmission dynamics of 2019 novel coronavirus (2019-nCoV). bioRxiv, 2020.2001.2025.919787. doi:10.1101/2020.01.25.919787

Majumder, M., \& Mandl, K. D. (2020). Early Transmissibility Assessment of a Novel Coronavirus in Wuhan, China (January 26, 2020). SSRN. doi:http://dx.doi.org/10.2139/ssrn.3524675

Mansfield, E., \& Hensley, C. (1960). THE LOGISTIC PROCESS - TABLES OF THE STOCHASTIC EPIDEMIC CURVE AND APPLICATIONS. Journal of the Royal Statistical Society Series B-Statistical Methodology, 22(2), 332-337. Retrieved from <Go to ISI >://WOS:A1960XF55400012

Nishiura, H., Jung, S.-m., Linton, N. M., Kinoshita, R., Yang, Y., Hayashi, K., . . . Akhmetzhanov, A. R. (2020). The Extent of Transmission of Novel Coronavirus in Wuhan, China, 2020. Journal of Clinical Medicine, 9(2), 330. Retrieved from https://www.mdpi.com/2077-0383/9/2/330

Shen, M., Peng, Z., Xiao, Y., \& Zhang, L. (2020). Modelling the epidemic trend of the 2019 novel coronavirus outbreak in China. bioRxiv, 2020.2001.2023.916726. doi:10.1101/2020.01.23.916726

Waggoner, P. E., \& Aylor, D. E. (2000). Epidemiology: A science of patterns. Annual Review of Phytopathology, 38, 71-+. doi:10.1146/annurev.phyto.38.1.71

Wang, C., Horby, P. W., Hayden, F. G., \& Gao, G. F. (2020). A novel coronavirus outbreak of global health concern. The Lancet. doi:10.1016/S0140-6736(20)30185-9

Wu, J. T., Leung, K., \& Leung, G. M. (2020). Nowcasting and forecasting the potential domestic and international spread of the 2019-nCoV outbreak originating in Wuhan, China: a modelling study. The Lancet. doi:10.1016/S0140-6736(20)30260-9

Wu, P., Hao, X., Lau, E. H. Y., Wong, J. Y., Leung, K. S. M., Wu, J. T., . . Leung, G. M. (2020). Real-time tentative assessment of the epidemiological characteristics of novel coronavirus infections in Wuhan, China, as at 22 January 2020. Eurosurveillance, 25(3), 2000044. doi:doi:https://doi.org/10.2807/1560-7917.ES.2020.25.3.2000044

Zhang, C., \& Wang, M. (2020a). MRCA time and epidemic dynamics of the 2019 novel coronavirus. bioRxiv, 2020.2001.2025.919688. doi:10.1101/2020.01.25.919688

Zhang, C., \& Wang, M. (2020b). Origin time and epidemic dynamics of the 2019 novel coronavirus. bioRxiv, 2020.2001.2025.919688. doi:10.1101/2020.01.25.919688

Zhao, S., Lin, Q., Ran, J., Musa, S. S., Yang, G., Wang, W., . . Wang, M. H. (2020a). Preliminary estimation of the basic reproduction number of novel coronavirus (2019- 
nCoV) in China, from 2019 to 2020: A data-driven analysis in the early phase of the outbreak. bioRxiv, 2020.2001.2023.916395. doi:10.1101/2020.01.23.916395

Zhao, S., Lin, Q., Ran, J., Musa, S. S., Yang, G., Wang, W., . . Wang, M. H. (2020b).

Preliminary estimation of the basic reproduction number of novel coronavirus (2019$\mathrm{nCoV}$ ) in China, from 2019 to 2020: A data-driven analysis in the early phase of the outbreak. International Journal of Infectious Diseases. doi:10.1016/j.ijid.2020.01.050 